\title{
Carbonising Forest Landscapes? Linking Climate Change Mitigation and Rural Livelihoods
}

\section{Gerald Leach and Melissa Leach}

\section{Introduction}

Mitigating global climate change and achieving sustainable livelihoods for the rural poor are both key international concerns. Carbon sinks, where forests and vegetation are used to absorb carbon dioxide from the atmosphere and store it as carbon, offer one potential route to link these. Increased forest and tree cover can bring major social, economic and environmental benefits to rural areas, as well as reducing net emissions of carbon dioxide. Yet sinks are also contentious, strongly opposed especially by major environmental nongovernmental organisations (NGOs) - as both ineffective in mitigation, distracting from its real challenges and as promoting styles of large plantation forestry that "carbonise landscapes" in ways that work against the interests of the poor.

How does this debate look if we start from the perspective of rural people's own uses, values and priorities around trees and forest landscapes? Longstanding work and experience around social aspects of forestry reveal the multiple roles of trees and forests in rural livelihoods, key dynamics in people-forest relations and a range of pre-conditions and issues which shape whether forestry interventions are genuinely pro-poor. In line with a recent review by Smith and Scherr (2002), it is suggested in this article that if such insights shape the selection and design of sink interventions, then they have the potential to bring huge benefits to rural people and their basic land, water and biomass resources, using new sources of carbon finance to improve rural livelihoods, climate change mitigation and resilience to the impacts of global warming.

But do the formal mechanisms available to promote carbon sinks - primarily the Clean Development Mechanism (CDM) of the Kyoto Protocol - encourage such positive interactions between climate change and livelihoods? This article reflects on what the CDM as currently designed can do, what it cannot do and where it fails completely. Although the limitations are severe, we suggest that they do not provide grounds for abandoning carbon sinks and their potential poverty links. Rather there is scope both for re-writing key aspects of the CDM - of particular pertinence just now, as its rules governing small-scale projects for poor people and communities are being drawn up in time for the 10th Conference of the Parties (COP 10) in December 2004 - and for a more realistic look at the circumstances in which the carbon route to enhancing forest livelihoods, among many other possibilities, is really appropriate.

\section{Debating carbon sinks}

Deforestation and unsustainable agricultural practices are a significant part of the global warming problem, contributing about 20 per cent of current greenhouse gas emissions. At the same time, forestry and agriculture could be part of the solution in the potential they offer for large carbon sinks. Appropriate land use, land-use change and forestry (LULUCF) activities can both reduce greenhouse gas emissions from land systems by protecting and conserving carbon in existing vegetation and soils and take up and store additional carbon from the atmosphere. Furthermore, carbon sinks can also facilitate "adaptation" as well as mitigation. As the World Bank puts it: 'Carbon finance represents a new financing source for revegetating drylands, 
providing alternative sources of energy and making drought-prone areas more resilient to climate change' (World Bank 2004).

In this respect, the potential synergies with poverty reduction and livelihoods are several-fold. Carbon sinks can contribute to land-use and land management changes that improve income from soils and vegetation and that enhance the resilience and adaptability of agro-ecosystems to climate change, helping counter associated development problems linked to water and health. Moreover, sink projects can generate income through the payments made for carbon sequestered or conserved, enabling poor people to participate in and gain from emerging carbon markets (World Bank 2004).

Carbon sinks are a topic of tense debate, however. Against these positive arguments, international environmental NGOs such as Greenpeace, Friends of the Earth, the World Wide Fund for Nature and the influential European umbrella organisation Climate Action Network (CAN) Europe, raise a range of deep objections to sinks as a mitigation strategy. First, they argue that sinks divert attention from the really major shifts that need to be made to mitigate climate change, including lifestyle and economic changes among the rich and in the North and the development of low-carbon energy systems based on efficiency and renewables. Under the CDM, they argue, sinks merely offset continued pollution and so put no pressure on the Annex 1 (rich) country polluters to change their practices. Objectors also argue that sinks are not permanent removers of carbon from the atmosphere:

... plants capture carbon only for as long as they survive. Once carbon is in the biosphere it will inevitably find its way one day into the atmosphere and enhance global warming. As a matter of simple science therefore, a carbon 'sink' is not equivalent to an emission cut [from burning fossil fuels]. (CAN Europe et al. 2003)

While there are certainly some grounds for these arguments, it can be countered that carbon sinks are not meant to be a replacement for other mitigation strategies, but a key complement to them and a vital way of "buying time" to effect the huge task of creating a global low-carbon energy system. In other words, both are needed.
A second core objection to forests as carbon sinks, of central relevance to our concerns, is that they encourage precisely the type of forestry development which works against poverty reduction: large, commercial monoculture plantations, which will drive out local people and bring a range of associated forms of social and environmental "devastation", such as biodiversity loss (see, e.g. CAN Europe et al. 2003). Several examples of such large-scale carbon sinks projects have become icons in this critical literature. For example:

In Brazil, Plantar S.A. has already begun expanding its vast eucalyptus tree plantations by another 23,000ha. Local small peasant communities have been opposed to the expansion of Plantar's eucalyptus tree plantations for many years. They have witnessed their lands slowly but surely dry up as new plantations encroach, followed by a slow process of seeing their wells drying out and their lands desiccated to a point where it does not support a meagre subsistence livelihood anymore. (Kill 2003)

Drawing on such examples, the European Union Forest Watch organisation, FERN, called on EU governments at COP 9 (December 2003) to boycott carbon credits originating from sinks projects:

If governments buy into these fake carbon credits, indigenous peoples and communities will be hit twice by climate change. First, they are likely to bear the brunt of the impacts caused by global warming and second the CDM will finance environmentally damaging tree plantations - the "green deserts" which communities have been struggling against for decades. (FERN 2004)

While there are risks that carbon finance could make way for industrial "forestry barons" to override local interests, using such extreme examples to make the case for "banning" sinks altogether may be throwing the baby out with the bathwater. It means abandoning the many beneficial possibilities which carbon sinks offer to link climate change mitigation with livelihood improvements. Furthermore, this type of project, like all CDM projects, is subject to confirmation by host country governments that it contribute to sustainable development. 
In this vein, "middle ground" discussions have emerged, which consider the social aspects of carbon sink forestry and seek to specify the conditions under which "win-win" scenarios, bringing benefits to rural livelihoods, are likely (e.g. Smith and Scherr 2002; Bass et al. 2000). These discussions can be helpfully informed by the mass of research and experience on interactions between people, land and trees, more generally, which has emerged over the last few decades.

\section{Livelihoods, landscapes and trees}

The multiple roles that trees play in rural livelihoods and in sustaining the resources or forms of "natural capital" that underpin them, are now thoroughly documented from localities around the world. In highly diverse ways, trees and forest areas provide vital subsistence products, ranging from foods such as fruit, leaves, nuts or wild game, to medicinal products and materials for construction, tools and household goods. Timber and non-timber forest products are often sold for cash income, with certain products providing key income flows to those who lack access to other sources of financial capital: whether the dependence of landless and tribal groups people on leaf and fodder sales in rural Gujarat (e.g. Shah and Shah 1995), or of women in parts of West Africa on non-timber forest products as sources of independent income (e.g. Falconer 1990). In some areas trees play key roles in reducing vulnerability, with tree-based foods and incomes providing vital buffers to seasonal shortages and contingencies caused by sudden life events (e.g. Chambers and Leach 1989).

Many rural people value trees in sustaining environmental services, contributing to shade, wind- and fire-breaks, to the productivity of soils and water sources and to the safeguarding of genetic resources. In semi-arid regions, especially, particular trees are valued for their roles in increasing soil productivity and land sustainability through nutrient recycling and by providing mulch and shade for crops, thus complementing agricultural production.

The particular roles and values of trees vary enormously according to context - social, economic, ecological - as do the ways in which trees and vegetation are used and managed. Some communities living in or near large forest areas, including many of the so-called "indigenous peoples" of Latin America and South-East Asia, have developed sophisticated ways of living with and enriching diverse forest ecologies to sustain livelihoods based to a large extent on forest product extraction (e.g. Poffenberger 1996). Other livelihood systems in humid and drier forest areas involve the conversion of forest land for farming. Farmers manage and sometimes enrich secondary forest fallows with valued species both to sustain soil productivity and to maintain flows of useful food products, building poles and so on. In such areas, or in drier savannahs, rural people frequently create concentrations of valued trees around their homesteads or settlements (e.g. Arnold and Dewees 1997). These range from trees planted along field boundaries or as intercrops, to the agro-forestry "home gardens" described for parts of Asia, to the peri-village forest "islands" of West Africa's forestsavannah transition zone, where villagers have used livestock, fire and soil management techniques to encourage the formation of dense vegetation to provide protection and shade for people and tree crops and a range of food and medicinal products (Fairhead and Leach 1996).

Across this huge diversity of local conditions, several general points emerge. First, it is clear that for rural people, trees and forest vegetation are part of multiple livelihoods and are incorporated within multi-use landscapes (Leach and Mearns 1988). Second, "management" extends beyond any simple dichotomy between "preserving natural forest" and "planting new trees". Third, patterns of interaction are often highly dynamic, as people adapt to ecological uncertainties - from climate change to the unpredictable ecosystem dynamics increasingly appreciated within "new ecology" - and to rapid shifts in market, demographic or social conditions which may make particular products, services or values desirable. They frequently involve social negotiations and conflicts between people with different resource values, livelihood priorities or rights of access; between men and women, longterm residents and more recent immigrants, or richer and poorer groups. Actual patterns of landscape change thus depend partly on the outcomes of such negotiations, as mediated by local institutions and broader policy frameworks. Present practices may build on the legacies of past adaptations, in 'dynamic forest landscapes' (Leach 2001).

Taken together with an appreciation of these forest-livelihood dynamics, the experiences with 
social and community forestry interventions that have built over the last few decades suggest a range of key lessons if these interventions are to be effective and genuinely to benefit the poor. These include the importance of starting with local interests in trees and vegetation and local perceptions that there is indeed a problem or need to enhance forest vegetation; a seemingly obvious point borne out by the numerous "failed" community forestry projects across the world that did not meet any local concern. Second, there is value in working with and building on local management techniques and processes, which are often socially and ecologically appropriate and cost-effective. Third, experience with community forestry has generated lessons about the importance of genuine participation in the shaping of plans and agendas and about the inclusion of marginal groups in negotiations, if interventions are to be sustainable and benefit rural livelihoods.

Fourth, issues of land and tree tenure and rights of access to products, are of key importance if people are to have the incentive and security to plant and protect trees and forests. Here, broader policies tend to be more significant than projects. In many cases, it has been the overhaul of restrictive, coloniallyderived forestry laws which denied farmers the right to own trees on their land that has unleashed processes of spontaneous farm tree planting. In Tanzania for example, legally transferring public forest land to villages has led to many beneficial forestry activities, from enrichment planting to more efficient charcoal production (Wiley and Mbeya 2001). In community, collaborative and joint forest management schemes, whether in Asia or Africa, broader policy changes, which enable communities to partner the state in forest management, or which enshrine legal recognition of "village forests", have been at least as significant as forms of technical and institutional intervention at the project level.

\section{Potential roles of forest carbon activities}

These perspectives and experiences can usefully help to shape the thinking around opportunities and routes to channel carbon payments to benefit rural livelihoods. In many respects, they support the arguments of Smith and Scherr (2002) concerning the scope for carbon forest projects which also bring livelihood benefits and the necessary conditions for these.
Smith and Scherr (2002) give a useful typology of possible types of carbon forest projects and assess the livelihood benefits - and risks - associated with each. They group these into two major strategies: afforestation and reforestation, in which additional forest is established to sequester and store carbon, and "prevented" (or reduced) deforestation, which protects standing forest carbon stocks that would otherwise be lost to the atmosphere. Under afforestation and reforestation, they include the large-scale industrial pulp or timber plantations that have been the focus of environmental NGOs' critique, agreeing that these promise few livelihood benefits and major risks. However, they also draw attention to several other possibilities: (a) agroforestry and community forest plantations, which would include tree-growing on farms and pastures, (b) agroforests in gardens and secondary forest fallows, which would include forms of fallow enrichment and (c) forest regeneration and rehabilitation. Most of the forms of tree management for livelihoods discussed in the last section could be fitted into one or another of these categories. Smith and Scherr suggest that carbon payments could facilitate these, if used to provide technical and marketing assistance, to pay necessary costs of forest establishment, protection or management and to pay farmers for carbon benefits produced. In the case of forest regeneration, they could compensate users excluded from the regenerating forest. They suggest that all three offer the potential for major livelihood benefits through carbon payments (on an individual or community basis), forest products and environmental services and minimal risks, provided there is secure local land/forest tenure and appropriate local organisational capacities. Their discussion of "prevented" deforestation is not included here, as this strategy has recently been ruled out of the CDM as a way of gaining carbon sink credits.

Others also emphasise the high potential of multispecies community level forestry and agroforestry as a form of "win-win", bringing both livelihood and climate change mitigation benefits, emphasising its high potential for restoring and improving the productivity of degraded or dryland areas (Richards 2003). While such forms of forestry have higher transaction costs and lower biomass productivity than industrial plantations, in aggregate their impact could be very large. As a rough, illustrative example, let us consider the potential of rehabilitating India's 
"wastelands" (see Balooni and Singh 2003). Estimates of wasteland in India range from 75 to 200 million ha. Chambers et al. (1989) cite a figure of 84 million ha, of which 35 million ha is private cultivated land and 49 million ha government-owned degraded lands, including village commons. If just a quarter of this land were afforested using multiple-use species of value for local incomes, food and fodder and assuming carbon yields of 3.2 tonnes Carbon/ha per year, the yield obtained in one set of village trials (Pal and Sharma 2001), this would give a carbon sink of roughly 70 million tonnes Carbon/year. This is a large sink, equivalent to about half of the UK's year 2000 emissions from fossil fuels (155 million tonnes Carbon/year) and a quarter of that for India (292 million tonnes Carbon/year) (Marland et al. 2002). Tree establishment costs can be high, so financial help is often needed, even though overall returns may be very good and complemented by a range of less-quantifiable benefits to livelihood diversification and resilience. In short, it seems that so long as the appropriate social and institutional conditions are met, then carbon sink activities have significant potential to bring both major climate change and livelihood benefits.

\section{Opportunities - and limits - of the Clean Development Mechanism}

Currently, the only potentially large mechanism or funding source for carbon sink activities in developing countries within the Framework Convention on Climate Change is the Kyoto Protocol's Clean Development Mechanism (CDM). The CDM and its role in relation to carbon sinks has an extremely complex history. What concerns us here is the extent to which it is geared to supporting the types of forestry activities which, as outlined above, have the potential to bring livelihood benefits.

The CDM as presently designed is able only to support some livelihood-relevant kinds of afforestation and reforestation (A\&R) carbon sink activities. In particular, it can support any form of $A \& R$ in which there is no substantial harvesting of wood products, including assisted natural regeneration, land reclamation, watershed protection, windbreaks and tree-growing to provide fruit, nuts, leaf fodder and so on.

As noted above, due to concerns that countries might be able to claim credits for what are actually business-as-usual activities, the CDM does not support "prevented" deforestation. This however, rules out potentially valuable schemes that might link forest conservation with multiple-use landscapes and compensatory livelihood activities. Nor does the CDM currently allow sink credits for any harvested products - even if these remain in use (for example, as construction timber) for centuries. This is because CDM sink projects are able to consider only those changes in carbon stocks that occur on the project site. Because of these two severe restrictions, we have, for example, the bizarre situation where a village that plants a woodlot to provide firewood which previously came from a local "natural" forest, would receive no carbon sink credit for their efforts to "save the forest" and its associated biodiversity. The credit for storing carbon in the woodlot is cancelled out by the carbon emissions from burning the firewood. The credit for leaving wood in the local forest instead of burning it as fuel is not allowed by the CDM rule that excludes prevented deforestation. In the case of West Africa's forest islands, to give another example, villagers' ongoing creation of peri-village forests would be excluded from CDM credits because the (disputed) "received wisdom" holds that these forests were disappearing relics in a deforesting landscape.

Even with the allowable A\&R activities, to qualify for CDM support, projects must pass through a complex set of scientific and bureaucratic hoops. These include the need to prove that there are real, measurable and long-term benefits related to the mitigation of climate change; to prove the additionality of net greenhouse gas emission reduction (or carbon sequestered), compared with a business-as-usual baseline; and to comply with a range of qualifying, certifying and monitoring procedures, including the requirement that projects 'assist in achieving sustainable development'. Because of the high transactions costs and forms of expertise needed to negotiate these hurdles, it has been suggested that, with respect to sinks, the CDM is strongly biased towards big commercial projects, of the kind so strongly criticised by environmental NGOs.

However, alternatives have been suggested. First, as Smith and Scherr (2002) argue, there is scope for "bundling" smaller projects and activities: individual farmers, villages or groups could collaborate in various ways to create a bundled project of sufficient size to bear the high transaction 
costs of getting a CDM project qualified, as well as helping to meet the high establishment costs for many types of small-scale forestry. There are many examples in the forestry sector more broadly, which could provide models for such "bundling", ranging from village-level cooperatives and alliances between individual growers such as the tree-growers cooperative societies fostered by Anand in India, to federations of community forestry groups such as those supported by the European Union in Guinea.

Second, COP 9, held in Milan in December 2003, agreed that "fast track" approval procedures should apply to sinks projects which are (a) small (under 8,000 tonnes of carbon fixed per year) and (b) run by poor communities or individuals. This move may do away with the need for cooperative and other bundling approaches, although this will not be clear until the proposed 'simplified modalities and procedures' are defined at COP 10, planned for December 2004.

The need to prove additionality of net carbon sequestered places major constraints. With many developing country land use and forestry activities, a baseline is virtually impossible to construct, because data are often lacking, because prevalent assumptions about "original" vegetation are often questionable and disputed (Leach and Mearns 1996) and because forestry activities do not transform static states, but form part of ongoing, highly dynamic processes of landscape change. In other situations, farmers' ongoing fallow enrichment and tree planting may be manipulating dynamic ecological processes over overlapping timescales that make baseline projections not only unconstructable, but irrelevant. If many of the most livelihood- and carbon-positive interactions between people, land and trees are to be eligible for CDM support, then the additionality rule needs to be reconsidered and rendered more sensitive to such dynamics.

Another major constraint is that the CDM apparently excludes policies. Article 12 of the Kyoto Protocol defines the CDM only in terms of "projects", even though it has often been "changes" in broader policy and legal frameworks that have had the most significant effects in enabling successful forest livelihood activities and which could have far greater effects in the future than any number of small projects. This restriction in the CDM thus suggests many missed opportunities.
Strictly speaking, the CDM rules do not seem to prevent the setting-up of a project to help a country implement new or changed policies, but there have been no examples of these so far and it is likely that such schemes would fail other CDM tests, especially measurement and verification of the resulting carbon sequestration.

Last but not least, the global potential of CDMsinks is constrained by the ruling that contributions from forestry CDM activities cannot exceed 1 per cent of Annex I country 1990 greenhouse gas emissions. This is only some 5-6 per cent of the greenhouse gas (GHG) emissions reduction that Annex 1 countries need to achieve in the first commitment period (2008-12). There is thus no risk, as some fear, that the developing world will be covered by vast areas of the rich world's pollutionavoiding "Kyoto Forests".

\section{Funding forest livelihoods through carbon?}

Given the current limitations of the CDM, it is worth asking what other climate-related funding sources might be available to promote positive interactions between land, trees and livelihoods. At present, the strongest potential appears to lie in two funds set up by the World Bank specifically designed to help small-scale projects get through the hoops of the CDM: the BioCarbon Fund and the Community Development Carbon Fund. Both are modelled on the Bank's existing Prototype Carbon Fund, the major funder so far of industrial forestry carbon sinks, in that private investors in the fund receive pro rata credits from projects associated with the funds. The BioCarbon Fund, with its first projects due in early 2004, is explicitly aimed at directing carbon finance to poverty reduction, livelihoodrelated environmental benefits and sustainable development. It invites applications not just for small-scale afforestation and agroforestry activities, but importantly, also for deforestation-reducing activities, from forest protection within multi-use landscapes to bush fire reduction. Funds such as these thus cut themselves off from the strict rules of the CDM and are able to fund activities that are socially and environmentally beneficial, but which do not meet the CDM's strict criteria. However, such funds are small at present: the World Bank estimates that the BioCarbon Fund will generate emission credits equalling around 4 million tonnes Carbon during the Kyoto Protocol's first commitment period 
2008-12, less than the carbon sequestration component of one single project involving industrial tree plantations - the controversial Brazilian Plantar project which claims 4.3 million tonnes. Moreover, if they are not grants but standard World Bank loans, then the projects would have somehow to generate revenue to repay the loan, inviting the problematic forms of indebtedness for which this type of Bank project has been criticised more generally, across a range of sectors.

In theory, it would be possible to develop still more lenient ways in which small forestry activities could access carbon funds, brokered through different institutional arrangements. Indeed, it is likely that the coming years will see a proliferation of schemes, involving diverse donor agencies, NGOs and public-private partnerships. While if sensitively drawn and with sufficient participation built in, these may well serve to increase the range of options open to poor people to enhance their livelihoods through accessing emergent carbon markets, some caution - or realism - is also in order.

First, as experience in the forestry sector - as indeed in other development arenas - would confirm, market-based mechanisms rarely work smoothly in the interests of the poor - or at least not without strong, appropriate forms of market governance and regulation. Many forestry and land use activities depend, for their success and livelihood benefits, on people having rights to resources and to shape landscapes as they see fit. It would be worth bringing aspects of the wider debate in development over rights-based versus market-based approaches

\section{References}

Arnold, J.E.M. and Dewees, P., 1997, Farms, Trees and Farmers. Responses to Agricultural Intensification, London: Earthscan

Balooni, K. and Singh, K., 2003, 'Financing of wasteland afforestation in India', Natural Resources Forum, Vol 27: 235-46

Bass, S., Dubois, O., Moura-Costa, P., Pinard, M., Tipper, R. and Wilson, C., 2000, 'Rural livelihoods and carbon management', IIED Natural Resource Issues Paper 1, London: International Institute for Environment and Development

CAN Europe, World Wide Fund for Nature, Greenpeace, Royal Society for the Protection of Birds, Friends of the Earth, 2003, 'Emissions into the climate change arena and debating more broadly on what alternative strategies might exist for linking livelihood improvements to climate change mitigation.

Second, it is important to recognise that much beneficial land use and forestry activity is already proceeding in the absence of major international finance, either with local investments and financing, or as spontaneous parts of farmers' ongoing livelihood strategies. Support to the rights, capabilities and autonomy of rural land users to shape and enrich their landscapes may require less, not more, in the way of external intervention, monitoring and imposed management plans, although it may benefit from supportive policy frameworks that allow these capabilities to flourish.

In short, it would be misguided to abandon carbon sinks altogether, on the grounds that they detract from "real" climate change mitigation and have, in famous cases, hurt the poor. On the contrary, many opportunities exist to develop carbon sinks that also benefit rural livelihoods, by building on and enhancing the many interests and strategies that rural people already have for living and working with land and trees. Taking up these opportunities will require some innovative (re)thinking both to overhaul those CDM rules that currently militate against pro-poor forestry and to devise new means for rural people to access carbon finance; but in parallel, some realistic debate is needed about the contexts in which such financing mechanisms are really the best way forward.

trading directive a significant step forward, say NGOs', Press Release, 2 July, www.environment daily.com/docs/30702b.doc, accessed 3 March 2004

Chambers, R. and Leach, M., 1989, 'Trees as savings and security for the rural poor', World Development, Vol 17 No 3

Chambers, R., Saxena, N.C. and Shah, T., 1989, To the Hands of the Poor, London: Intermediate Technology Publications

Fairhead, J. and Leach, M., 1996, Misreading the African Landscape: Society and Ecology in a ForestSavannah Mosaic, Cambridge: Cambridge University Press

Falconer, J., 1990, 'The major significance of "minor" forest products: local people's uses and 
values of forests in the West African humid forest zone', Community Forestry Note 6, Rome: FAO

FERN, 2004, 'Forest fraud: say no to fake carbon credits', European Union Forest Watch (FERN), Issue 82, February, www.fern.org

Kill, J., 2003, 'The sinking bottom line', CAN Europe 'Hotspot' Newsletter, Issue 30, November, www.climnet.org/hotspot/HOTSPOT_ISSUE_30 .pdf, accessed 3 March 2004

Leach, M., 2001, 'Plural perspectives and institutional dynamics: challenges for community forestry', International Journal of Agricultural Resources, Governance and Ecology, Vol 1 Nos 3/4: 223-43

Leach, G. and Mearns, R., 1988, Beyond the Woodfuel Crisis: People, Land and Trees in Africa, London: Earthscan

Leach, M. and Mearns, R., 1996, The Lie of the Land: Challenging Received Wisdom on the African Environment, London: James Currey; New York: Heinemann

Marland, G., Boden, T.A. and Andres, R.J., 2002, Global, Regional and National Fossil Fuel $\mathrm{CO}_{2}$ Emissions, Oak Ridge: Carbon Dioxide Information $\&$ Analysis Center, http://cdiac.esd.ornl.gov/ trends/emis/em_cont.htm, accessed 1 March 2004

Pal, R.C. and Sharma, A., 2001, 'Afforestation for reclaiming degraded village common land: a case study', Biomass \& Bioenergy, 21: 35-42
Poffenberger, M. (ed.), 1996, Communities and Forest Management: A Report of the IUCN Working Group on Community Involvement in Forest Management, with recommendations to the Intergovernmental Panel on Forests, Cambridge, UK: The World Conservation Union

Richards, M., 2003, 'Poverty reduction, equity and climate change: challenges for global governance', ODI Natural Resource Perspectives 83, April

Shah, M.K. and Shah, P., 1995, 'Gender, environment and livelihood security: an alternative viewpoint from India', IDS Bulletin, Vol 26 No 1: 75-82

Smith, J. and Scherr, S., 2002, 'Forest carbon and local livelihoods: assessment of opportunities and policy recommendations', Occasional Paper 37, Bogor, Indonesia: Center for International Forestry Research, www.cifor.cgiar.org/ publications/pdf_files/OccPapers/OP-037.pdf, accessed 4 February 2004

Wiley, L.A. and Mbeya, S., 2001, Land, People and Forests in Eastern and Southern Africa at the Start of the 21st Century: Impact of Land Relations on the Role of Communities in Forest Future, Nairobi: IUCN Eastern Africa Regional Office, e-mail: mail@iucnearo.org

World Bank, 2004, About the Biocarbon Fund, http://carbonfinance.org/biocarbon/home.cfm, accessed 5 April 2004 